\title{
MILD SELF-DECLARED SIDE EFFECTS OF BOOSTED DARUNAVIR ASSOCIATED WITH OTHER ANTIRETROVIRALS IN ROMANIAN HIV-1 INFECTED PATIENTS
}

\author{
Ruxandra C. MARIN ${ }^{1}$, Adrian STREINU-CERCEL ${ }^{2,3}$, Simona BUNGAU ${ }^{1,4} \bowtie$ \\ ${ }^{1}$ Doctoral School of Biological and Biomedical Sciences, University of Oradea, Oradea, Romania \\ 2 "Carol Davila” University of Medicine and Pharmacy, Infectious Diseases Department, Bucharest, \\ Romania \\ 3 "Matei Bals" National Institute of Infectious Diseases, Bucharest, Romania \\ ${ }^{4}$ Faculty of Medicine and Pharmacy, University of Oradea, Oradea, Romania
}

Received 12 July 2021, Accepted 21 Aug 2021

https://doi.org/10.31688/ABMU.2021.56.3.05

\begin{abstract}
Introduction. Antiretroviral therapy (ART) is used in human immunodeficiency virus (HIV)-infected patients, to suppress viral replication and slow disease progression. The side effects of ART, milder or more serious, frequently occur, thus the main challenge for specialists is to find a balance between the benefits of long-term viremia suppression and the risks of toxicity. The objective of the study was to compare the frequency of mild side effects after administration of a regimen containing darunavir (DRV) boosted with ritonavir (RTV) (DRV/r $600 \mathrm{mg} / 100 \mathrm{mg}$, twice daily), vs DRV boosted with cobicistat (COBI) (DRV/c -800 $\mathrm{mg} / 150 \mathrm{mg}$, once a day) and perform a profile of the patient at risk of developing these types of adverse reactions during ARV treatment.
\end{abstract}

Materials and methods. 462 patients were enrolled in the study and divided into two groups: 384 received DRV/r, and $78 \mathrm{DRV} / \mathrm{c}$. This was a retrospective,

\section{Résumé}

Effets secondaires légers auto déclarés du darunavir renforcé associés à d'autres antirétroviraux chez les patients roumaines infectés par le HIV-1

Introduction. La thérapie antirétrovirale (ART) est utilisée chez les patients infectés par le virus de l'immunodéficience humaine (HIV), pour supprimer la réplication virale et ralentir la progression de la maladie. Les effets secondaires de l'ART, plus légers ou plus graves, surviennent fréquemment, ainsi le principal défi pour les spécialistes est de trouver un équilibre entre les avantages de la suppression de la virémie à long terme et les risques de toxicité.

L'objectif de l'étude était de comparer la fréquence des effets secondaires légers après l'administration d'un schéma thérapeutique contenant du darunavir (DRV) boosté par du ritonavir (RTV) (DRV/r $600 \mathrm{mg} / 100 \mathrm{mg}$, deux fois par jour), vs DRV boosté par du cobicistat ( 
non-interventional study using the database of the National Institute of Infectious Diseases "Prof. Dr. Matei Bals", Bucharest, Romania. The self-declared mild side effects were collected from patients' medical files and a comparison between the frequency of these in the two groups have been made. The main self-declared mild side effect was statistically correlated with the characteristic parameters of the cohort.

Results. The statistical description of the most frequent self-declared mild side effects in the two groups showed that all parameters were found in a greater proportion in DRV/r group than in DRV/c group, with a statistically significant difference of $p<0.05$. Myalgia and sleep disorders correlate strongly positive $(\mathrm{p}<0.01)$ with age, and fatigue correlates strongly positive with age and with number of ARV regimens $(\mathrm{p}<0.01)$, and positively with pills' burden $(\mathrm{p}<0.05)$.

Conclusions. The results of this study demonstrated that ART regimens containing DRV/c have a higher tolerability than those containing DRV/r. They also emphasize the importance of the management of mild self-declared side effects, to increase patients' adherence to treatment.

Keywords: antiretroviral therapy, darunavir, ritonavir, cobicistat, mild side reactions.

\section{List of abbreviations:}

ADRs - adverse drug reactions

AIDS - acquired immunodeficiency syndrome

ART - antiretroviral therapy

ARV - antiretroviral drug (antiretroviral)

COBI - cobicistat

CYP450 - P450 cytochrome

DRV - darunavir

EI - entry inhibitor

HIV - human immunodeficiency virus

HIV-1 - human immunodeficiency virus, type 1

II - integrase inhibitor

NRTI - nucleoside/nucleotide reverse transcriptase inhibitors

NNRTI - non-nucleoside reverse transcriptase inhibi-

tor

PI - protease inhibitor

RNA - ribonucleic acid

RTV - ritonavir

SMPC - summary of product characteristics
COBI) (DRV/c - $800 \mathrm{mg} / 150 \mathrm{mg}$, une fois par jour) et réaliser un profil du patient à risque de développer ces types d'effets indésirables au cours du traitement ARV. Matériels et méthodes. 462 patients ont été inclus dans l'étude et divisés en deux groupes : 384 ont reçu le $\mathrm{DRV} / \mathrm{r}$ et $78 \mathrm{DRV} / \mathrm{c}$. Il s'agissait d'une étude rétrospective non interventionnelle utilisant la base de données de l'Institut National des Maladies Infectieuses «Prof. Dr Matei Bals», Bucarest, Roumanie. Les effets secondaires légers autodéclarés ont été collectés à partir des dossiers médicaux des patients et une comparaison entre leur fréquence dans les deux groupes a été effectuée. Le principal effet secondaire léger auto-déclaré était statistiquement corrélé aux paramètres caractéristiques de la cohorte.

Résultats. La description statistique des effets secondaires légers autodéclarés les plus fréquents dans les deux groupes a montré que tous les paramètres étaient retrouvés en plus grande proportion dans le groupe $\mathrm{DRV} / \mathrm{r}$ que dans le groupe $\mathrm{DRV} / \mathrm{c}$, avec une différence statistiquement significative de $p<0,05$. La myalgie et les troubles du sommeil sont fortement corrélés positivement $(\mathrm{p}<0,01)$ avec l'âge, et la fatigue est fortement corrélée positivement avec l'âge et avec le nombre de schémas ARV $(\mathrm{p}<0,01)$, et positivement avec la charge de pilules $(\mathrm{p}<0,05)$.

Conclusions. Les résultats de cette étude ont démontré que les schémas thérapeutiques antirétroviraux contenant du DRV/c ont une tolérance plus élevée que ceux contenant du DRV/r. Ils soulignent également l'importance de la gestion des effets secondaires légers auto-déclarés, pour augmenter l'adhésion des patients au traitement.

Mots-clés: thérapie antirétrovirale, darunavir, ritonavir, cobicistat, effets secondaires bénins. 


\section{INTRODUCTION}

Antiretroviral therapy (ART) is an aggressive treatment strategy intended to suppress viral replication and slow disease progression of human immunodeficiency virus (HIV). It involves combinations of multiple antiretroviral drugs (ARV), most commonly 2 nucleoside/nucleotide reverse transcriptase inhibitors (NRTI) and either a non-nucleoside reverse transcriptase inhibitor (NNRTI) or protease inhibitor (PI). ART has revolutionized the treatment and prognosis of HIV-infected patients, delaying the progression to AIDS and reducing transmission, mortality, and rates of opportunistic infections. However, the side effects of ART, milder or more serious, are a common problem faced by specialists. The treatment of HIV infection has to find the balance between the benefits of long-term viremia suppression and the risks of toxicity. Due to side effects, more than half of patients change the regimen during the first months of treatment, but also later on, reaching dozens of regimens throughout their lives, until there are no longer therapeutic options. About 20\% of patients refuse to start ART because of fear of side effects ${ }^{1}$.

The adoption of fixed-dose combinations and single tablet regimens plays a crucial role in achieving patient adherence and compliance to antiretroviral therapy².

Darunavir (DRV) is very effective for therapy-experienced patients with limited options, due to its impressive potency in the presence of PI-resistance mutations ${ }^{3}$. It belongs to the protease inhibitors (PI) class, cornerstone of antiretroviral regimens, which have contributed to therapeutic success. Many studies have demonstrated the effectiveness of DRV against HIV-1 and this antiretroviral drug has become an important component of ART. It has a high affinity for the HIV-1 protease, binds strongly to it, forming a stable complex due to flexible conformation and skeletal interactions ${ }^{4}$.

In Romania, PI are used in combination with low doses of pharmacokinetic enhancers, ritonavir (RTV) $100 \mathrm{mg}$ or cobicistat (COBI) $150 \mathrm{mg}$ as first-line agents in regimens for naive and experienced HIV-positive patients. Pharmacokinetic enhancers increase the plasma concentration of DRV, making it more effective. Combined regimens increase also the tolerability by maintaining the plasma concentration in the effective area, without fluctuations exceeding Cmax value, which would lead to drug-toxicity reactions. The patient's adherence with the dosage, by reducing the number of daily administrations, is added. Food restrictions are also reduced.
RTV (in low dose of 100/ $200 \mathrm{mg}$ ) was the first enzyme inhibitor used to enhance an $\mathrm{PI}^{5}$. RTV strongly inhibits cytochrome P450 (CYP450) at the intestinal and hepatic level, the 3A4 isomorph and the glycoprotein $\mathrm{P}$, increasing the elimination half-life and the absorption of the DRV, when co-administrated. It has its own antiretroviral activity, being both an inhibitor and an enzyme inducer. This results in disadvantages such as the development of resistant strains and increased risk of side effects. The latter are caused by the molecule itself but are also related to drug-drug interactions. Furthermore, the tolerability problems of RTV have already been demonstrated in several studies $^{6}$.

The RTV's disadvantages led to the development of another enhancer, cobicistat (COBI), a more selective structural analogue of RTV, an enzyme inhibitor only, with no antiretroviral activity of its own. Another major advantage with direct consequences in patients' adherence is that the DRV was co-formulated with COBI in fixed dose, as a single tablet (DRV/c $-800 \mathrm{mg} / 150 \mathrm{mg})$.

A study demonstrated a comparable pharmacokinetic profile following DRV $800 \mathrm{mg}$ co-administered with cobicistat $150 \mathrm{mg}$ once daily ${ }^{7}$, to those of DRV/r $800 \mathrm{mg} / 100 \mathrm{mg}$ once daily, even if the plasma concentration of DRV is $30 \%$ lower when enhanced with COBI. Bioequivalence of DRV administered as a fixed-dose combination with $\mathrm{COBI}$ was demonstrated under fasted or fed conditions ${ }^{8}$.

Beyond ART's benefits, regardless of the ARV associated, side effects still significantly influence patients' adherence, increasing the risk of virologic, immunological and tolerability failure. Adverse drug reactions (ADRs), mild or more serious, associated with ART can reverse the gains of therapy, resulting in poor health outcomes. There is a need of an improved understanding of specific ART-related ADRs that influence virologic and immunological response, and also the patients' adherence to the therapy. In a previous study, it was demonstrated that the adverse events during ART are the most important determinants of adherence?

The OBJective OF THE STUDY was to compare the frequency with which mild side effects occur after administration of a regimen containing DRV boosted with RTV (DRV/r $600 \mathrm{mg} / 100 \mathrm{mg}$, twice daily), vs DRV boosted with COBI (DRV/c - $800 \mathrm{mg} / 150 \mathrm{mg}$, once a day). The study also performed a profile of a patient at risk of developing all these types of adverse reactions during ARV treatment, by statistically correlating the main self-declared mild side effect with the characteristic parameters for the cohort. 


\section{Materials AND MEthod}

This was a retrospective, non-interventional study, evaluating a cohort of 462 Romanian HIV-infected patients, enrolled in the database of the National Institute of Infectious Diseases "Prof. Dr. Matei Bals", Bucharest, Romania. The two-arms study has been carried on between October 2017 - December 2020. The cohort was divided into two groups. 384 patients represented the first group and received in the regimen, besides other ARV, DRV booted with RTV (DRV/r $600 \mathrm{mg} / 100 \mathrm{mg}$, twice daily), while 78 patients, representing the second group, received DRV booted with COBI (DRV/c - $800 \mathrm{mg} / 150 \mathrm{mg}$, once a day). The duration of the treatment, on the last regimen should have been at least three months before the evaluation.

Age over 18 years, ability to discern, the presence in the regimen of the DRV in combination with RTV or COBI, duration of the current therapeutic scheme of at least three months, represented criteria for including patients in the study. The criteria for exclusion were as follows: age under 18 years, clear clinical signs of organ decompensation, lack of discernment, lack of clinical evaluations since the current therapeutic scheme started, pregnancy and breastfeeding.

Side effects have been encoded according to Medical Dictionary for Regulatory Activities. The adverse events considered to be mild in this study were nausea/vomiting, rush, eczema, sleeping disorders, myalgia, headache, fatigue and hypersensitivity reactions. These reactions were recorded by clinicians during routine medical anamnesis.

The statistical analysis was performed using the SPSS Statistics 20.0.0 program (SPSS Inc., Chicago, IL, USA), for the entire cohort, but also separately for each group. One or more of the following statistical methods have been used: mean, standard deviation, the Pearson correlation coefficient for the quantitative comparison study between two variables; Student's t Test, expressed by the coefficient t; analysis of variance (ANOVA) F, with statistical significance noted with Sig, to check the influence of qualitative factors, explained by the coefficient $\mathrm{F}$ for three or more independent groups or pairs. $p<0.05$ was considered as a significant statistical result. The sign "." indicates a negative correlation, inversely proportional between the two parameters concerned.

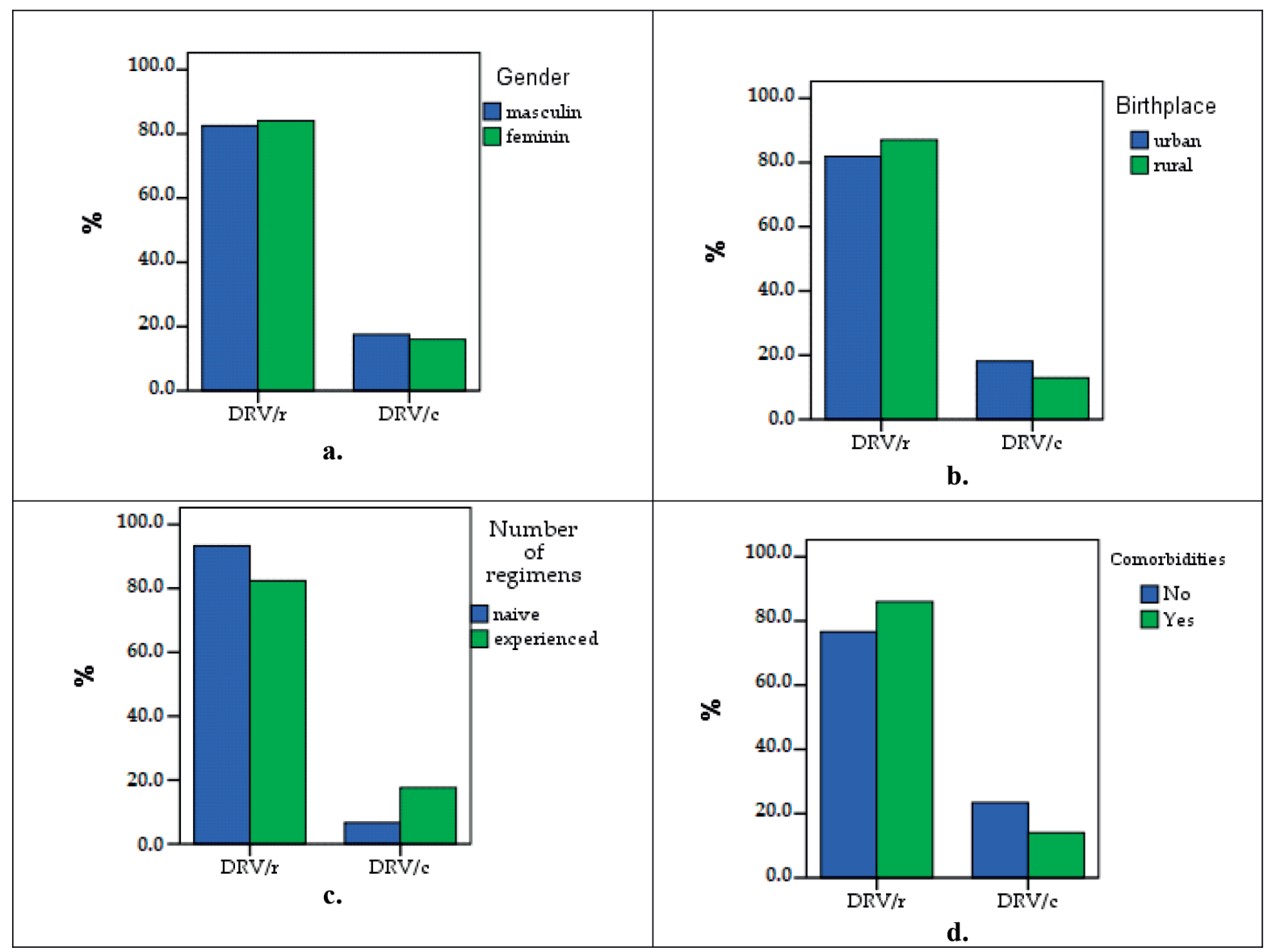

Figure 1. Patients' distribution in the two groups according to: $\mathrm{a}$ - gender; $\mathrm{b}$ - birthplace; $\mathrm{c}$ - naive/experienced; $\mathrm{d}$ - comorbidities yes/no (SPSS) 
The agreements of the Management Commission (9/5861 / 04.05.2021) and Bioethics Commission (C05865/ 04.05.2021) were obtained, for the use of the Institute's database and the waiver of the need for informed consent. The study was conducted in accordance with the ethical principles set out in the Helsinki Declaration and was consistent with the Good Clinical Practice guidelines ${ }^{10}$.

\section{Results}

There were no statistically significant differences in the demographic characteristics between the two assessed groups. Women accounted for $38.50 \%$ of the patients of the DRV/r and $35.90 \%$ of the DRV/c group. The remaining percentages represented men: $61.50 \%$ in the DRV/r group and $64.10 \%$ in the DRV/c. Statistically, $\mathrm{F}=0.878, \mathrm{t}=74.544$ and $\mathrm{p}=0.001$ were obtained. The average age of the patients in the cohort

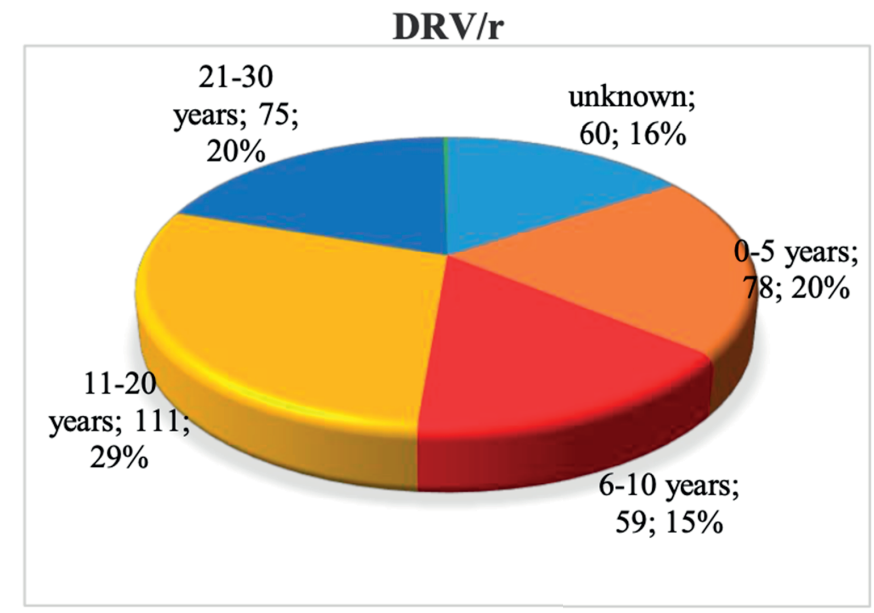

a.

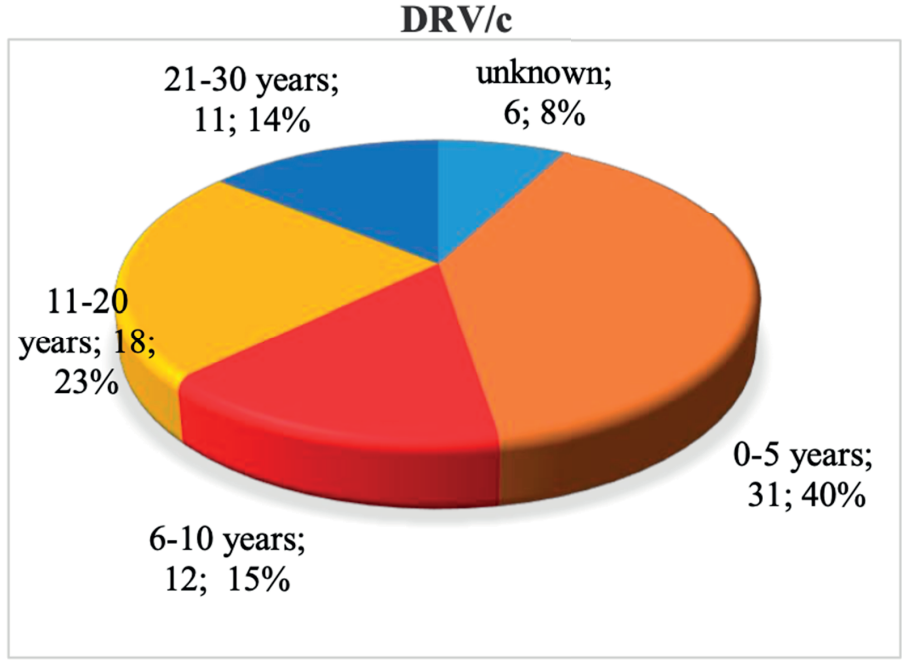

b.

Figure 2. Patients' distribution in the two groups by duration of infection (in years) (Microsoft, Excel) was 39.27 years (SD 11.32), in the $1^{\text {st }}$ group being 39.41 years (SD 11.50) and in the $2^{\text {nd }}$ group - 38.57 years (SD 10.45). Considering the birthplace, in the $\mathrm{DRV} / \mathrm{r}$ group, $75.52 \%$ were from urban area, $24.48 \%$ from rural area, with $82.05 \%$ of urban area and $17.95 \%$ of rural areas for DRV/c. Statistically, $\mathrm{F}=7.264, \mathrm{t}=62.591$, $\mathrm{p}=0.001$ were obtained.

The vast majority of patients in the cohort (93.5\%) were therapeutic experienced patients: $92.7 \%$ in the $\mathrm{DRV} / \mathrm{r}$ group and $97.43 \%$ in the $\mathrm{DRV} / \mathrm{c}$ group. Naive patients represented $6.5 \%$ in the entire cohort and were distributed as follows: $7.3 \%$ in the DRV/r group and $2.56 \%$ in the DRV/c group. The description of the patients by gender, birthplace, number of regimens and presence of comorbidities, from the two groups, is presented in Figure 1.

Considering the duration of infection in the group exposed to the $\mathrm{DRV} / \mathrm{r}$, the mean value was 11.05 ( $\mathrm{SD} \pm 9.16)$, in the $\mathrm{DRV} / \mathrm{c}$ group the mean value was $9.17( \pm 8.19)$ and $10.74(\mathrm{SD} \pm 9.02)$. Statistically, comparing the two groups, $\mathrm{F}=2.792, \mathrm{t}=25.576, \mathrm{p}=0.001$ have been obtained (Figure 2).

Considering the duration of ART, for the $\mathrm{DRV} / \mathrm{r}$ group, the mean value was 11.17 (SD \pm 6.15$)$, for $\mathrm{DRV} / \mathrm{c} 9.57(\mathrm{SD} \pm 6.37)$, total cohort $10.90( \pm 6.21)$. Statistically, comparing the values for the two groups, we obtained $\mathrm{F}=0.003, \mathrm{t}=37.699$ and $\mathrm{p}=0.001$. The distribution of patients by duration of ART (years) in the two groups is depicted in Figure 3.

The patients in the two groups were also characterized in terms of the number of regimens experienced since diagnosis. In the entire cohort, the mean value was 8.88 $(\mathrm{SD} \pm 7.23)$, for $\mathrm{DRV} / \mathrm{r}$ group the mean value was $9.09(\mathrm{SD} \pm 7.42)$ and for $\mathrm{DRV} / \mathrm{c}$, the mean value was 7.89 (SD 7.23). In the current regimen, associated with the DRV and the studied enhancers (RTV or COBI), patients received at least one other ARV of a different therapeutic class. The description of the cohort according to HIV therapy, as number and type of therapeutic classes, is presented in Table 1.

The most frequently self-declared mild side effects, following the administration of the current therapeutic regimen, occurred at gastro-intestinal level: nausea/ diarrhea were self-declared by $47.10 \%$ of the patients in the DRV/r group and by $29.40 \%$ in DRV/c group, followed by myalgia $(45.80 \%$ vs. $12 \%$ of the patients in $\mathrm{DRV} / \mathrm{r}$ group and DRV/c group); fatigue 


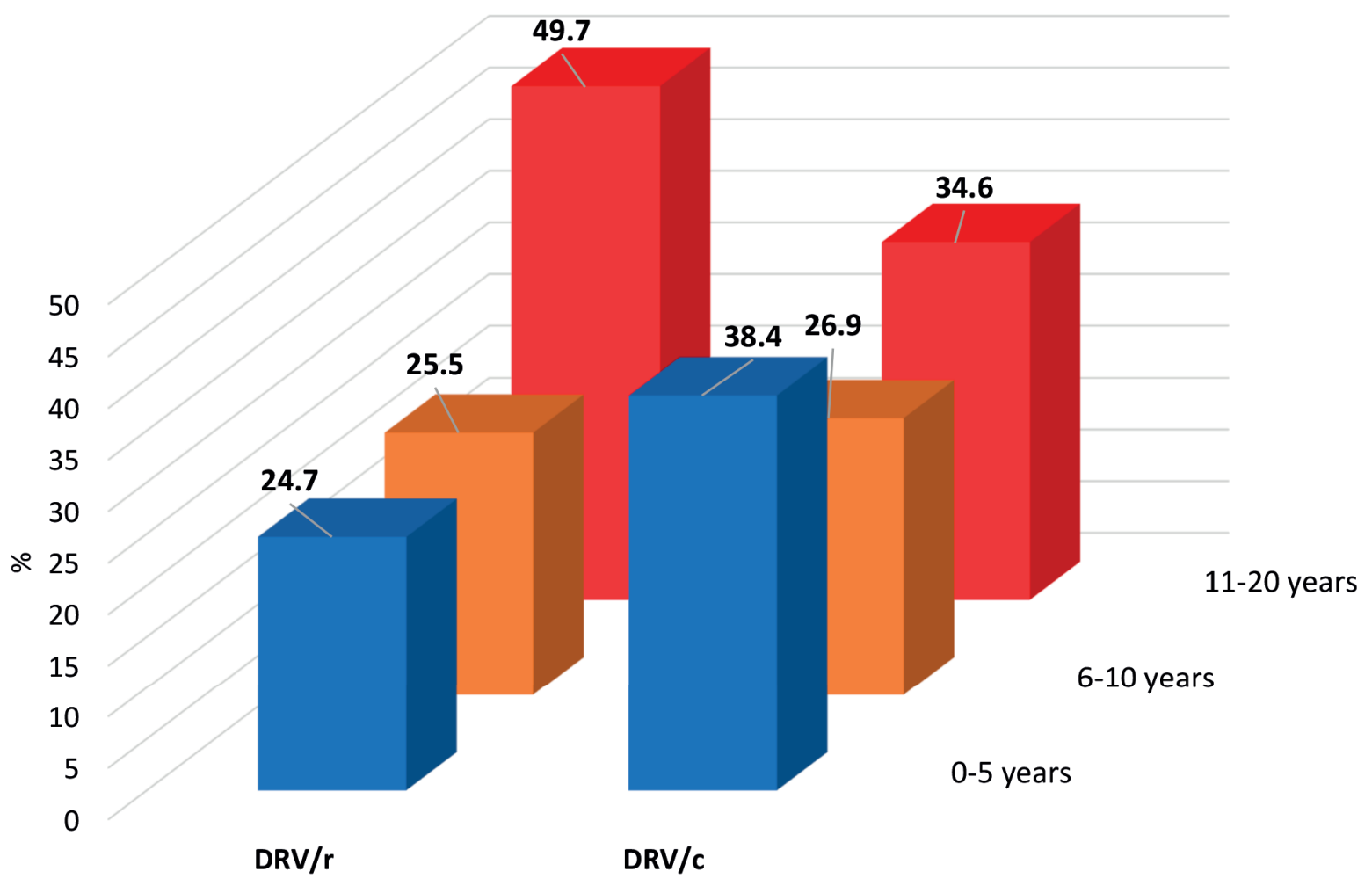

Figure 3. Patients' distribution in the two groups by duration of ART (Microsoft, Excell)

was invoked by $45.10 \%$ of patients in the DRV/r group compared to $7.60 \%$ in the DRV/c. The most common skin reactions were eczema and rush, most patients with such reactions were in the DRV/r group, $32.50 \%$, compared to $11.50 \%$ in the DRV/c group. Hypersensitivity reactions to drug were less frequent, with $9.60 \%$ of patients in the first group and $3.80 \%$ in the second one reporting the symptom. Headache occurred in $30.70 \%$ of patients exposed to the $\mathrm{DRV} / \mathrm{r}$ vs. only $7.6 \%$ of those taking DRV/c. $29.10 \%$ of patients in the DRV/r group and $16.60 \%$ of the DRV/c group self-declared sleeping disorders occurring during treatment's administration. Pharyngitis was declared only by $15.80 \%$ patients in DRV/r group (Figure 4).

Noting with 0 - the absence of symptoms and with 1 - their presence, the comparison between the two groups is statistically significant, $p=0.001$ for all the parameters, as observed in Table 2. Applying independent $\mathrm{t}$ Student test and ANOVA variation test, the following results were obtained: nausea/diarrhea $\mathrm{t}=19.092, \mathrm{~F}=66.710$, Sig. $=0.004$; eczema/rush $\mathrm{t}=13.724, \mathrm{~F}=109.934$, Sig. $=0.001$; myalgia $\mathrm{t}=17.626$ $\mathrm{F}=405.383$, Sig. $=0.001$; sleeping disorders $\mathrm{t}=13.076$, $\mathrm{F}=29.421$, Sig. $=0.023$; headache $\mathrm{t}=13.005, \mathrm{~F}=149.032$, Sig. $=0.001$; fatigue $t=17.076 \mathrm{~F}=759.361$, Sig. $=0.001$; pharyngitis $\mathrm{t}=8.374, \mathrm{~F}=89.166$, Sig. $=0.001$ and hypersensitivity reactions $\mathrm{t}=6.610, \mathrm{~F}=12.342$, Sig. $=0.098$
Table 1. Therapeutic classes associated with DRV/r or DRV/c presented comparatively for the two groups

\begin{tabular}{|c|c|c|c|c|}
\hline \multirow{2}{*}{ Associated ARV classes } & \multicolumn{2}{|c|}{$\begin{array}{c}D R V / r \\
n=384\end{array}$} & \multicolumn{2}{|c|}{$\begin{array}{c}D R V / c \\
n=78\end{array}$} \\
\hline & $n$ & $\%$ & $n$ & $\%$ \\
\hline 1NNRTI & 4 & 1.04 & 0 & 0 \\
\hline 1NNRTI+1II & 22 & 5.72 & 0 & 0 \\
\hline $1 \mathrm{PI}+1 \mathrm{II}$ & 16 & 4.16 & 0 & 0 \\
\hline 1NNRTI+1EI & 4 & 1.04 & 0 & 0 \\
\hline 1NRTI+1NNRTI & 22 & 5.72 & 0 & 0 \\
\hline 1NRTI+1II & 23 & 5.98 & 4 & 5.12 \\
\hline 1NRTI & 6 & 1.56 & 0 & 0 \\
\hline 1NRTI+1NNRTI+1PI+1II & 3 & 0.78 & 0 & 0 \\
\hline 2NRTI+1NNRTI & 4 & 1.04 & 0 & 0 \\
\hline 2NRTI+1NNRTI+1II & 1 & 0.26 & 0 & 0 \\
\hline 2NRTI & 252 & 65.62 & 70 & 89.74 \\
\hline 2NRTI+1II & 20 & 5.20 & 2 & 2.56 \\
\hline 2NRTI+1PI & 1 & 0.26 & 0 & 0 \\
\hline 3NRTI+1II & 1 & 0.26 & 0 & 0 \\
\hline 3NRTI+1NNRTI & 1 & 0.26 & 0 & 0 \\
\hline 3NRTI & 1 & 0.26 & 0 & 0 \\
\hline 3NRTI+2II & 0 & 0 & 1 & 1.28 \\
\hline 4NRTI & 3 & 0.78 & 0 & 0 \\
\hline 4NRTI+1II & 0 & 0 & 1 & 1.28 \\
\hline
\end{tabular}

Legend: NRTI - nucleoside reverse transcriptase inhibitor, NNRTI - non-nucleoside reverse transcriptase inhibitor, PI - protease inhibitor, II - integrase inhibitor, EI - entry inhibitor, $\mathrm{n}$ - number of patients in the group. 


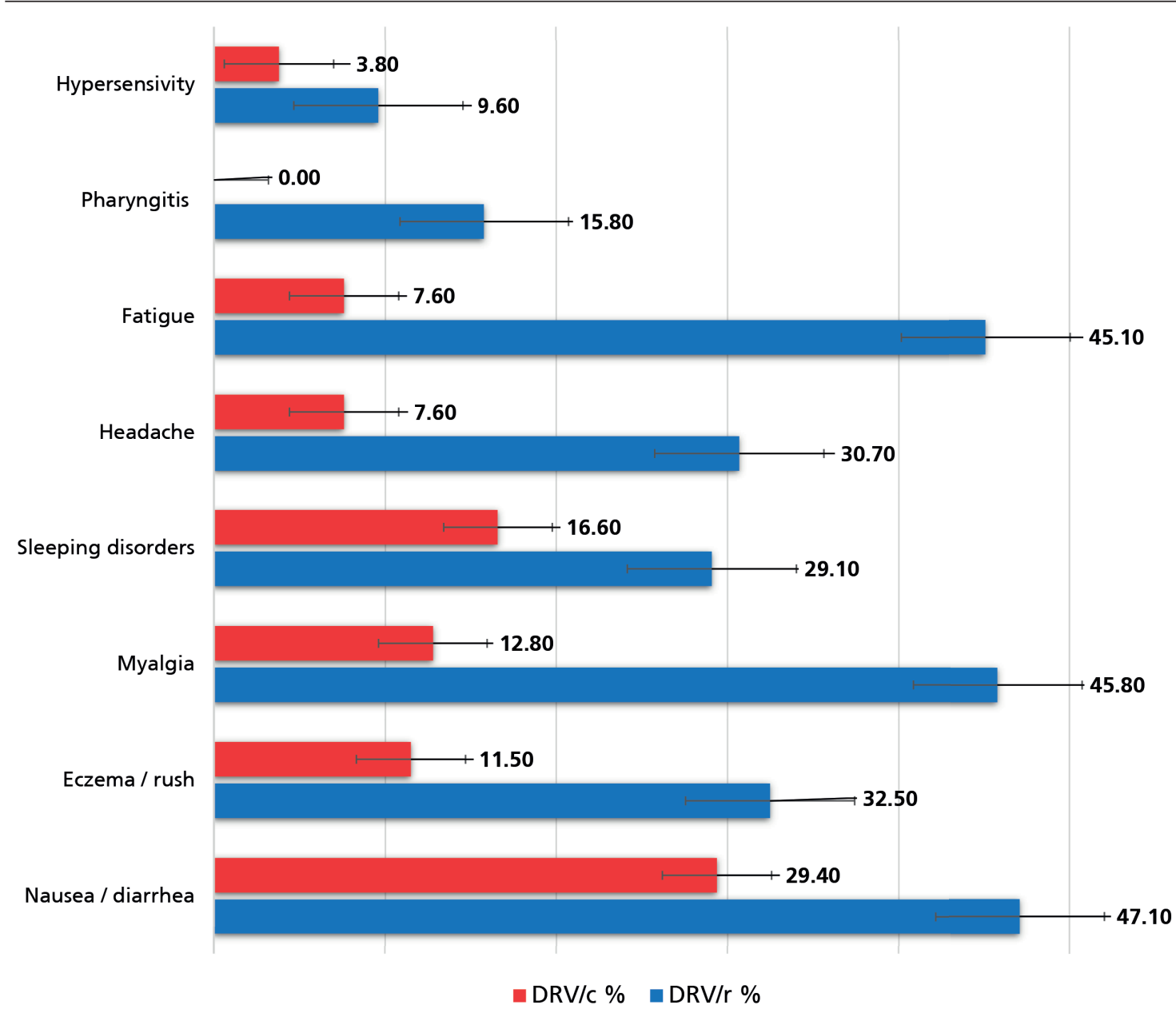

Figure 4. Distribution of common mild side effects, comparatively in the two groups (Microsoft, Excel)

Table 2. Statistical description of the most frequently self-declared mild side effects in the two groups, for $\mathrm{p}=0.001$

\begin{tabular}{|c|c|c|c|c|c|c|c|}
\hline \multirow{2}{*}{ Variables } & \multicolumn{2}{|c|}{ Mean } & \multicolumn{2}{|c|}{$S D$} & \multirow[b]{2}{*}{$F$} & \multirow[b]{2}{*}{ Sig. } & \multirow[b]{2}{*}{$t$} \\
\hline & $\begin{array}{c}D R V / r \\
n=384\end{array}$ & $\begin{array}{c}\mathrm{DRV/c} \\
n=78\end{array}$ & $\begin{array}{l}D R V / r \\
n=384\end{array}$ & $\begin{array}{c}\text { DRV/c } \\
n=78\end{array}$ & & & \\
\hline Nausea/Diarrhea & 0.5 & 0.3 & 0.5 & 0.5 & 66.710 & 0.004 & 19.092 \\
\hline Eczema/Rush & 0.3 & 0.1 & 0.5 & 0.3 & 109.934 & 0.001 & 13.724 \\
\hline Myalgia & 0.5 & 0.1 & 0.5 & 0.3 & 405.383 & 0.001 & 17.626 \\
\hline Sleeping disorders & 0.3 & 0.2 & 0.5 & 0.4 & 29.421 & 0.023 & 13.076 \\
\hline Headache & 0.3 & 0.1 & 0.5 & 0.3 & 149.032 & 0.001 & 13.005 \\
\hline Fatigue & 0.5 & 0.1 & 0.5 & 0.3 & 759.361 & 0.001 & 17.076 \\
\hline Pharyngitis & 0.2 & 0.0 & 0.4 & 0.0 & 89.166 & 0.001 & 8.374 \\
\hline Hypersensitivity & 0.1 & 0.0 & 0.3 & 0.2 & 12.342 & 0.098 & 6.610 \\
\hline
\end{tabular}

(Table 2). The graphical representation of the mean values of the most frequently self-declared mild side effects can be seen comparatively between the two groups in Figure 5.

In order to determine the profile of the patient at risk of developing mild side effects studied, at ARV administration, cohort demographic parameters were correlated with the frequency of mild side effects.
The study obtained the following results, with statistical significance:

- myalgia correlates strongly positively $(\mathrm{p}<0.01)$, directly proportional to the patients' age,

- sleeping disorders and age correlate strongly positively $(\mathrm{p}<0.01)$

- fatigue relates strongly positively $(\mathrm{p}<0.01)$ to age, to number of ARV regimens and with a 


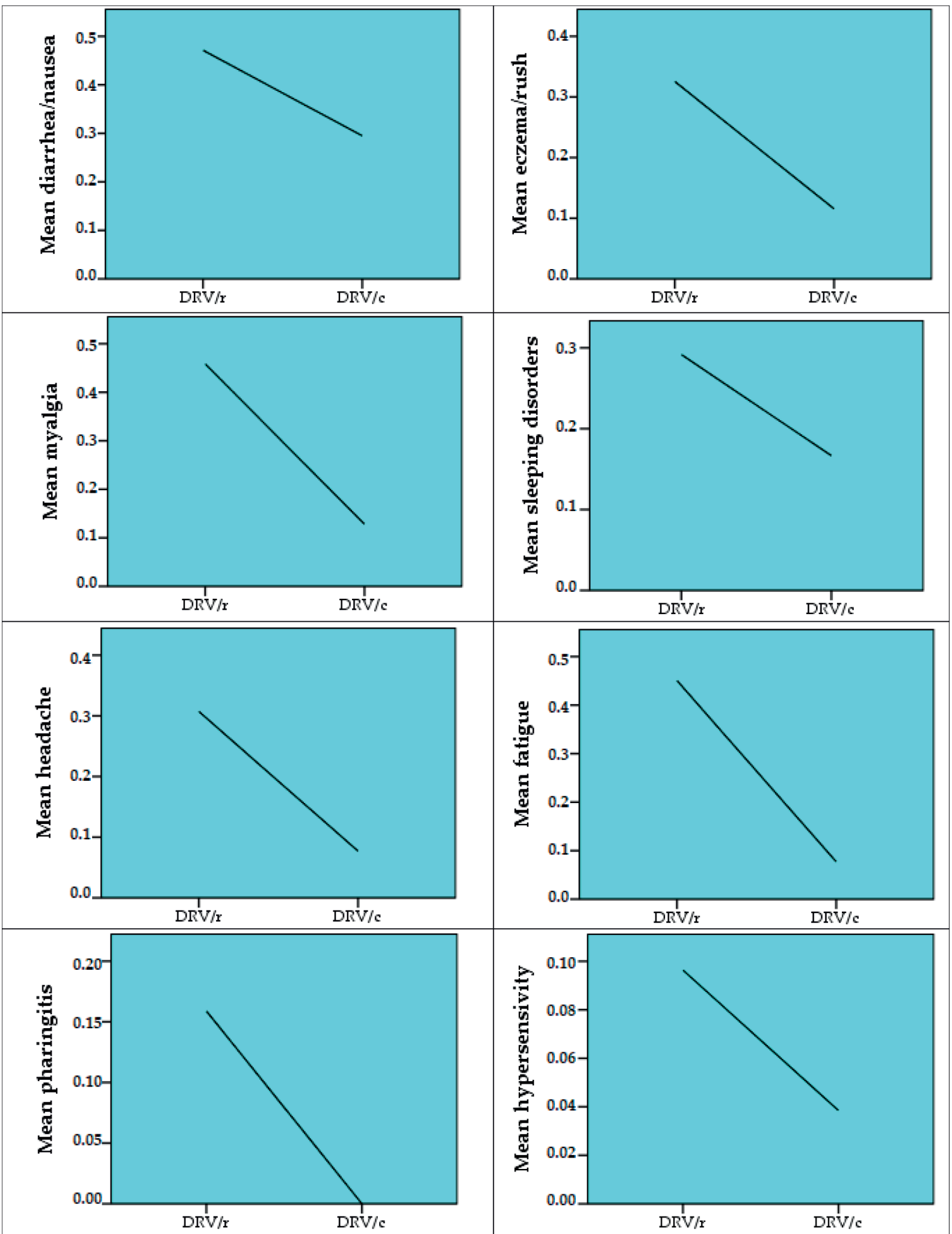

Figure 5. The mean values of the most frequently self-declared mild side effects comparing the two groups (SPSS) 
Archives of the Balkan Medical Union

Table 3. Pearson correlation between the risk of mild side effects and demographic parameters in the cohort

\begin{tabular}{|c|c|c|c|c|c|c|c|c|}
\hline Variables & $\begin{array}{l}\text { Nausea/ } \\
\text { diarrhea }\end{array}$ & Eczema/rush & Myalgia & $\begin{array}{l}\text { Sleeping } \\
\text { disorders }\end{array}$ & Headache & Fatigue & Pharyngitis & Hypersensitivity \\
\hline Age & $\begin{array}{c}0.084 \\
(p=0.073)\end{array}$ & $\begin{array}{c}-0.001 \\
(p=0.982)\end{array}$ & $\begin{array}{c}0.326^{* *} \\
(p=0.001)\end{array}$ & $\begin{array}{c}0.206^{* *} \\
(\mathrm{p}=0.001)\end{array}$ & $\begin{array}{c}0.075 \\
(p=0.106)\end{array}$ & $\begin{array}{c}0.163^{* *} \\
(p=0.001)\end{array}$ & $\begin{array}{c}0.084 \\
(\mathrm{p}=0.071)\end{array}$ & $\begin{array}{c}0.025 \\
(p=0.585)\end{array}$ \\
\hline $\begin{array}{c}\text { Duration of } \\
\text { ART }\end{array}$ & $\begin{array}{c}0.012 \\
(\mathrm{p}=0.789) \\
\end{array}$ & $\begin{array}{c}-0.003 \\
(p=0.946)\end{array}$ & $\begin{array}{c}-0.019 \\
(\mathrm{p}=0.690)\end{array}$ & $\begin{array}{c}0.022 \\
(\mathrm{p}=0.632)\end{array}$ & $\begin{array}{c}0.001 \\
(\mathrm{p}=0.984)\end{array}$ & $\begin{array}{c}0.033 \\
(\mathrm{p}=0.484)\end{array}$ & $\begin{array}{c}-0.036 \\
(p=0.441)\end{array}$ & $\begin{array}{c}0.003 \\
(\mathrm{p}=0.952)\end{array}$ \\
\hline $\begin{array}{c}\text { Number of } \\
\text { ARV regimens }\end{array}$ & $\begin{array}{c}0.046 \\
(p=0.319) \\
\end{array}$ & $\begin{array}{c}0.034 \\
(p=0.462) \\
\end{array}$ & $\begin{array}{c}0.003 \\
(p=0.950) \\
\end{array}$ & $\begin{array}{c}0.040 \\
(p=0.394) \\
\end{array}$ & $\begin{array}{c}0.041 \\
(p=0.379) \\
\end{array}$ & $\begin{array}{c}0.127^{* *} \\
(\mathrm{p}=0.006)\end{array}$ & $\begin{array}{c}0.036 \\
(p=0.440) \\
\end{array}$ & $\begin{array}{c}-0.028 \\
(p=0.548) \\
\end{array}$ \\
\hline $\begin{array}{c}\text { Number of } \\
\text { comorbidities }\end{array}$ & $\begin{array}{c}-0.013 \\
(p=0.775)\end{array}$ & $\begin{array}{c}-0.044 \\
(p=0.340)\end{array}$ & $\begin{array}{c}0.019 \\
(p=0.679)\end{array}$ & $\begin{array}{c}-0.037 \\
(p=0.425)\end{array}$ & $\begin{array}{c}0.080 \\
(p=0.085)\end{array}$ & $\begin{array}{c}-0.079 \\
(p=0.090)\end{array}$ & $\begin{array}{c}-0.001 \\
(p=0.983)\end{array}$ & $\begin{array}{c}0.019 \\
(p=0.689)\end{array}$ \\
\hline Pill's burden & $\begin{array}{c}0.056 \\
(p=0.229) \\
\end{array}$ & $\begin{array}{c}-0.037 \\
(p=0.442) \\
\end{array}$ & $\begin{array}{c}0.017 \\
(p=0.709) \\
\end{array}$ & $\begin{array}{c}0.032 \\
(p=0.493)\end{array}$ & $\begin{array}{c}-0.028 \\
(p=0.543)\end{array}$ & $\begin{array}{c}0.110^{*} \\
(p=0.018)\end{array}$ & $\begin{array}{c}-0.009 \\
(p=0.842)\end{array}$ & $\begin{array}{c}-0.024 \\
(p=0.607)\end{array}$ \\
\hline
\end{tabular}

$\mathrm{p}$ - statistical significance, ${ }^{*}$ - statistical significance $\mathrm{p}<0.05,{ }^{* *}$ - statistical significance $\mathrm{p}<0.01,{ }^{-}$, , indicates a negative correlation, inversely proportional between the two parameters concerned.

statistical significance of $\mathrm{p}<0.05$ with the pills burden (Table 3).

The other parameters do not reach the threshold of statistical significance when correlating to the demographic characteristics of the patient cohort.

\section{Discussion}

Simplified treatment regimens, with as little pill burden as possible, few side effects and maximum efficacy represent the goals in the management of antiretroviral therapy.

This study revealed a number of self-declared mild side effects after administration of ARV, which are not related to changes in serum or metabolic markers, but they depend on the perception of each patient: nausea/diarrhea, eczema/rush, myalgia, sleeping disorder, headache, fatigue, pharyngitis, or hypersensitivity reaction. For clinicians, the challenge is to manage patients' attitude toward these reactions, most of which disappearing after a few weeks of administration. The long-term persistence of these reactions may compromise the success of therapy, by losing patients' adherence to treatment. The study results have shown that virologic and immunological response to therapy remains favorable in most patients. It is difficult to say, however, whether or what percentage of patients in therapeutic failure (HIV-1 RNA load $>1000$ copies/mL and/or CD4 lymphocytes $<0-199$ cells $/ \mathrm{mm}^{3}$ ) is caused by discontinued therapy. At the clinical anamnesis, an extremely high percentage of patients (on average of $91.5 \%$ ) declared that they had taken the treatment according to the dosage prescribed.

Long before the outbreak of the HIV/AIDS epidemic, sociologists described how everyone`s perceptions of the disease and of different symptoms influences their attitude and behavior toward treatment ${ }^{11}$.
Regarding ART, fear or a previous bad experience with a drug, for example side effects on zidovudine, have been shown to lead to decreased adherence ${ }^{12}$. Data from another study confirm that the perception of adverse symptoms developed in the first four months of a regimen is a critical determinant of adherence. The way a patient relates to drugs' side effects, whether or not related to the toxicity of the drug, is a good indicator of patients' difficulties in managing the daily life course of the treatment ${ }^{13}$.

It is not possible to establish precisely if the self-declared reactions were caused by the ARV. However, the present study has shown that all the symptoms occur with a higher incidence in the regimen containing RTV than with COBI as pharmacokinetic enhancer. The differences have statistical significance, $\mathrm{p}<0.01$ for all parameters. This underlines that the patients exposed to DRV/c have a better tolerability profile than those taking DRV/r, thus leading to a greater adherence to treatment. Previous studies that have evaluated the tolerability profile of RTV confirm the results of this study ${ }^{14}$.

Gastrointestinal reactions, nausea and vomiting were present in $47.2 \%$ of patients in the DRV/r group and in $29.5 \%$ of the subjects in the DRV/c group. Both the ART, in particular protease inhibitor regimens ${ }^{15}$, and various opportunistic infections with protozoa, fungi, viruses and bacteria are responsible for these symptoms.

Still, the nature of HIV-related diarrhea has shifted from being predominantly a consequence of opportunistic infection to being largely a side effect of ART agents. Previous studies have shown that a quarter of $\mathrm{HIV}^{+}$patients present diarrhea, that has a negative impact on their life quality ${ }^{16}$. The negative effect on quality of life in patients with ART-related diarrhea is profound; diarrhea may also increase the risk of poor adherence to treatment, with potentially 
serious effects on viral suppression and increased risk of drug resistance ${ }^{17}$.

However, in a study carried out on a cohort of patients in Italy, in whom both PI and NRTI were administered, it was shown that diarrhea does not decrease immediately the patient adherence, although this type of reaction is extremely frequent among patients and does not disappear after the first weeks of administration ${ }^{13}$. PI is also responsible for the appearance of nausea, and RTV is well-known to have this side effect, with $20 \%$ of patients accusing it after RTV administration ${ }^{14}$.

Patients in this study have self-declared the occurrence of rush and eczema. 32.55\% (DRV/r) compared to $11.53 \%(\mathrm{DRV} / \mathrm{c})$ patients accused these symptoms. The average of the values for the first group is $0.32(\mathrm{SD} \pm 0,46)$ compared to an average of $0.11( \pm$ SD 0.32$)$ for the second group. The comparative results obtained when carrying out the $t$ Student and ANOVA tests, the F coefficients are statistically relevant $(\mathrm{p}<0.05)$, with a high risk of occurrence in the DRV/r group and thus lower safety for those exposed to the RTV. The results of this study are consistent with those demonstrated by other studies. In 2014, the study carried out by Nishijima and colleagues pointed out that these skin reactions occur frequently when taking DRV, especially when it is enhanced with RTV. However, most patients can get over these symptoms when associating an oral antihistamine or corticosteroid treatment ${ }^{18}$.

Before this study, data on the prognosis and incidence of skin rashes and eczema after ARV administration were limited. The only information came from the summary of product characteristics (SMPC) $)^{19,20}$. More recently, DRV has been reported to cause rash in $6.7 \%$ of patients, with severe symptoms in less than $1 \%$ of them, especially when boosted with RTV ${ }^{21}$. According to the same SMPCs, myalgia is a side effect that can occur very frequently in patients exposed to RTV and frequently when administrating $\mathrm{COBI}^{20,22}$.

Our study recorded the occurrence of these reactions in $45.9 \%$ of patients who received DRV/r and in only $12.9 \%$ of those in the second group, DRV/c. Comparing the two groups, the results have statistically significance, the mean value for the first group is 0.45 , while for the second is 0.33 . Although the risk of these symptoms is present for both regimens, the incidence is much higher in subjects in DRV/r group. Although frequently self-declared by patients, no targeted studies have been carried out on this subject. Fatigue and sleep disorders go hand in hand, often declared by patients under ARV treatment ${ }^{23,24}$. In our study, $45.1 \%$ of patients in the group exposed to the $\mathrm{DRV} / \mathrm{r}$ and only $7.7 \%$ of those exposed to the DRV/c complained of chronic fatigue during treatment. The statistical difference between the two groups is extremely high, with $\mathrm{F}=759.361$ and $\mathrm{t}=17.076$, significance $p<0.001$. Sleep disorders were present in $29.2 \%$ of the subjects from the DRV/r group and $16.7 \%$ in the $\mathrm{DRV} / \mathrm{c}$ group.

A study carried out among HIV-positive teenagers showed that chronic fatigue is perceived as problematic, having a considerable impact on their daily lives, affecting their ability to concentrate at school or socialize with their peers ${ }^{25}$. However, in order to be able to demonstrate the link between ART and sleeping disorders, further studies are required to compare a cohort exposed to ART with one not exposed. In the first group, (DRV/r) 30.72\% self-declared headaches as mild symptom, while in the second group (DRV/c) only $7.69 \%$ of subjects recalled its presence during treatment. The statistical difference is important, the significance being $\mathrm{p}<0.001$, with ANOVA coefficient $\mathrm{F}=149.032$ and $\mathrm{t}$ Student test coefficient, $\mathrm{t}=13.005$.

Headache is one of the most common complaints in this patient cohort. Some previous studies have found a correlation between the HIV infection itself and primary headache disorders, others demonstrated more of a link to secondary causes, caused by opportunistic infections often associated with HIV. All patients in these studies were taking ART ${ }^{26,27}$.

However, data are lacking regarding the prevalence and diagnostic characteristics of headache among HIV patients in the current ART era. Studies have obtained divergent findings regarding the prevalence of headache disorders among HIV patients, all of them being conducted before the wide spread proliferation of $\mathrm{ART}^{28}$.

The only patients who mentioned pharyngitis (during ARV's administration) were those in the group exposed to RTV, $15.88 \%$. The difference between groups is statistically significant, with a mean value of 0.15 vs. $0.00, t=8.374$ and $F=14.667$. In addition, the SMPC mentions that side effects such as pharyngitis, coughing or oropharyngeal pain may occur very frequently with the long term RTV administration ${ }^{20}$. We did not find any previous studies that had investigated the prevalence of this symptom among $\mathrm{HIV}^{+}$patients.

Hypersensitivity reactions to therapy occurred with a rate of less than $10 \%$ across the cohort, but with a significant difference between the two groups, 9.63\% (DRV/r) versus 3.84\% (DRV/c). Both results are in line with the frequency stipulated in the $\mathrm{SMPCs}^{20,22}$. Comparing the two groups, the results have statistical significance, $\mathrm{p}<0.001, \mathrm{t}=6.610$ and $F=12.342$. Previous studies have shown that hypersensitivity reactions and allergies occur 100 times more 
frequently in people infected with HIV than in the general population ${ }^{29}$. Many ARV or drugs used for the opportunistic infections can cause drug hypersensitivity reactions, which vary in severity, clinical manifestations and frequency. These reactions are not only seen with the older ones, but also with the newer molecules recently introduced in therapy. The most frequently incriminated therapeutic classes are NNRTI and PI. Abacavir causes hypersensitivity reaction in $2-4 \%$ of patients, reactions that can even have a lethal end $\mathrm{d}^{30}$.

The current study also performed a patient profile with a risk of developing all these types of adverse reactions during ARV treatment. We have statistically correlated the main self-declared mild side effect with the characteristic parameters for the cohort. The results showed that myalgia and sleep disorders have a higher risk of occurring in patients with a higher pill' s burden. The heavier the pill's burden, the more often they occur. Chronic fatigue correlates strongly positively $(\mathrm{p}<0.01)$ directly proportional to the pill burden. The more pills a patient takes once, the greater the risk of fatigue. Fatigue is also positively correlated $(\mathrm{p}<0.05)$ with the number of comorbidities. The more diseases a HIV-infected patient suffers from, the more often fatigue occurs.

\section{Conclusions}

ART regimens containing DRV/c appear to have a higher tolerability than those containing DRV/r. This was statistically proven in the present study by frequency of mild side effects, which are less often self-declared by patients who have received DRV/c. Patient adherence depends on the frequency and intensity of side effects. The results of our study strongly emphasize that management of mild side effects should be an important part of the antiretroviral therapy, in order to promote adherence.

\section{Author Contributions:}

Conceptualization, R.C.M.; methodology, R.C.M. and S.B.; software, R.C.M.; validation, S.B..; formal analysis, R.C.M.; investigation, R.C.M.; resources, R.C.M.; data curation, R.C.M.; writing-original draft preparation, R.C.M. and S.B.; writing-review and editing, R.C.M., and S.B.; visualization, A.S.C. and S.B.; supervision, A.S.C. and S.B.; project administration, S.B. All authors have read and agreed with the final version of this article.

\section{Compliance with Ethics Requirements:}

"The authors declare no conflict of interest regarding this article"
"The authors declare that all the procedures and experiments of this study respect the ethical standards in the Helsinki Declaration of 1975, as revised in 2008(5), as well as the national law. Informed consent was obtained from all the patients included in the study"

"No funding for this study"

\section{Acknowledgements:}

None

\section{References}

1. Anastasi JK, Capili B. Nausea and vomiting in HIV/AIDS. Gastroenterol Nurs. 2011;34:15-24.

2. Curran A, Pérez-Valero I, Moltó J. Rezolsta ${ }^{\circledR}$ (Darunavir/ Cobicistat): First Boosted Protease Inhibitor Co-formulated with Cobicistat. AIDS Rev. 2015;17:114-120.

3. Marin RC, Behl T, Negrut N, Bungau S. Management of antiretroviral therapy with boosted protease inhibitors Darunavir/Ritonavir or Darunavir/Cobicistat. Biomedicines. 2021;9:313.

4. Serious $P$, Threatening OL. Highlights of prescribing information. Interactions.5:7-2.

5. King JR, Wynn H, Brundage R, Acosta EP. Pharmacokinetic enhancement of protease inhibitor therapy. Clin Pharmacokinet. 2004:43:291-310.

6. Hsu A, Granneman GR, Bertz RJ. Ritonavir. Clinical pharmacokinetics and interactions with other anti-HIV agents. Clin Pharmacokinet. 1998;35:275-291.

7. Kakuda TN, Opsomer M, Timmers M, et al. Pharmacokinetics of darunavir in fixed-dose combination with cobicistat compared with coadministration of darunavir and ritonavir as single agents in healthy volunteers. J Clin Pharmacol. 2014;54:949-957.

8. Kakuda TN, Van De Casteele T, Petrovic R, et al. Bioequivalence of a darunavir/cobicistat fixed-dose combination tablet versus single agents and food effect in healthy volunteers. Antivir Ther. 2014;19:597-606.

9. Lennox JL, Landovitz RJ, Ribaudo HJ, et al. Efficacy and tolerability of 3 nonnucleoside reverse transcriptase inhibitor-sparing antiretroviral regimens for treatment-naive volunteers infected with HIV-1: a randomized, controlled equivalence trial. Ann Intern Med. 2014;161:461-471.

10. Guideline ICHH. Integrated addendum to ICH E6 (R1): guideline for good clinical practice E6 (R2). Current Step. 2015;2:1-60.

11. Heitman E. The influence of values and culture in responses to suffering. NLN Publ. 1992:81-103.

12. Muma RD, Ross MW, Parcel GS, Pollard RB. Zidovudine adherence among individuals with HIV infection. AIDS Care. 1995; 7:439-447.

13. Duran S, Spire B, Raffi F, et al. Self-reported symptoms after initiation of a protease inhibitor in HIV-infected patients and their impact on adherence to HAART. HIV Clin Trials. 2001;2:38-45.

14. Lucas GM, Chaisson RE, Moore RD. Highly active antiretroviral therapy in a large urban clinic: risk factors for virologic failure and adverse drug reactions. Ann Intern Med. 1999;131:81-87.

15. Sherman DS, Fish DN. Management of protease inhibitor-associated diarrhea. Clin Infect Dis. 2000;30:908-914. 
16. Dikman AE, Schonfeld E, Srisarajivakul NC, Poles MA. Human immunodeficiency virus-associated diarrhea: still an issue in the era of antiretroviral therapy. Dig Dis Sci. 2015;60:2236-2245.

17. Macarthur RD. Management of noninfectious diarrhea associated with HIV and highly active antiretroviral therapy. Am J Manag Care. 2013;19:s238-245.

18. Nishijima T, Gatanaga H, Teruya K, et al. Skin rash induced by ritonavir-boosted darunavir is common, but generally tolerable in an observational setting. J Infect Chemother. 2014;20:285-287.

19. European Medicine Agency. Prezista. https://www.ema. europa.eu/en/documents/overview/prezista-epar-summary-public_ro.pdf (accesesd 03 June 2021)

20. European Medicine Agency. Norvir. https://www.ema.eu ropa.eu/en/documents/overview/norvir-epar-summary-public_ro.pdf (accesesd 03 June 2021)

21. Clotet B, Bellos N, Molina JM, et al. Efficacy and safety of darunavir-ritonavir at week 48 in treatment-experienced patients with HIV-1 infection in POWER 1 and 2: a pooled subgroup analysis of data from two randomised trials. Lancet. 2007;369:1169-1178.

22. European Medicine Agency. Rezolsta. https://www.ema. europa.eu/en/documents/overview/rezolsta-epar-medicine-overview_ro.pdf (accesesd 03 June 2021)
23. Hudson AL, Portillo CJ, Lee KA. Sleep disturbances in women with HIV or AIDS: efficacy of a tailored sleep promotion intervention. Nurs Res. 2008;57:360-366.

24. Pence BW, Barroso J, Leserman J, Harmon JL, Salahuddin N. Measuring fatigue in people living with HIV/AIDS: psychometric characteristics of the HIV-related fatigue scale. AIDS Care. 2008;20:829-837.

25. Loades ME, Coetzee B, Du Toit S, Kagee A. '... But i'm still tired': the experience of fatigue among South African adolescents receiving antiretroviral therapy. AIDS Care. 2018;30:746-750.

26. Kirkland KE, Kirkland K, Many WJ, Jr., Smitherman TA. Headache among patients with HIV disease: prevalence, characteristics, and associations. Headache. 2012;52:455-466.

27. Mirsattari SM, Power C, Nath A. Primary headaches in HIV-infected patients. Headache. 1999;39:3-10.

28. Lipton RB, Feraru ER, Weiss G, et al. Headache in HIV-1-related disorders. Headache. 1991;31:518-522.

29. Tymchuk CN, Currier JS. The safety of antiretroviral drugs. Expert Opin Drug Saf. 2008;7:1-4.

30. Hughes CA, Foisy MM, Dewhurst N, et al. Abacavir hypersensitivity reaction: an update. Ann Pharmacother. 2008;42:387-396. 